\title{
Glycine to Creatinine Ratio Measurement
}

National Cancer Institute

\section{Source}

National Cancer Institute. Glycine to Creatinine Ratio Measurement. NCI Thesaurus.

Code C158221.

The determination of the ratio of glycine compared to creatinine present in a sample.

The measurement may be expressed as a ratio or percentage. 